\title{
A prototype development of visual perception diagnosis games for autism children
}

Helmi Adly Mohd Noor ${ }^{1, *}$, Faaizah Shahbodin ${ }^{2}$, Gede Pramudya Ananta ${ }^{2}$, Cik Ku Nuraini Che Ku Mohd ${ }^{2}$, Syarifah Nadiyah Razali ${ }^{3}$, Mohd Sazali Khalid ${ }^{4}$, Rahimah Kassim ${ }^{1}$, Fauziah Abdul Rahman ${ }^{1}$, Zirawani Baharum ${ }^{1}$

${ }^{1}$ Malaysian Institute of Industrial Technology, Universiti Kuala Lumpur, Johor, Malaysia

${ }^{2}$ Department of Interactive Media, Faculty of Information and Communication Technology, Universiti Teknikal Malaysia Melaka, Malaysia

${ }^{3}$ Kolej Komuniti Selandar, Melaka, Malaysia

${ }^{4}$ Southeast Asian Ministers of Education Organization, Regional Centre for Education in Science and Mathematics, Pulau Pinang, Malaysia

\section{A R T I C LE IN F O}

\section{Article history:}

Received 6 November 2016

Received in revised form

11 January 2017

Accepted 15 January 2017

\section{Keywords:}

Autism

Autistic children

Serious games

Special education

Visual perception

\begin{abstract}
A B S T R A C T
In order to minimize the negative effects of autism, early identification and diagnosis are the solutions to get students on the right road to dealing with the problems related to autism and overcoming them. The objective of this research is to develop serious games as a tool for special education teachers to diagnose visual perception problems in autistic students. The development of the visual perception diagnosis games is using the Chalfant diagnosis theory. These diagnostic tools show that it assist and help teachers to diagnose their autism students without the teachers needing to have some experience and knowledge of diagnosing visual perception. This prototype will be a high-tech solution to diagnosing visual perception problems designed for autistic children.
\end{abstract}

(C) 2017 The Authors. Published by IASE. This is an open access article under the CC BY-NC-ND license (http://creativecommons.org/licenses/by-nc-nd/4.0/).

\section{Introduction}

Autism is undetected from birth (Wan and Hisham, 2013) and only when the child is around 18 months of age a brain disorder could be detected (Kanner, 1967). Autism means a condition that causes children to concentrate on their own world. Autism interferes with mental development of children incorporating speech, communication, social interaction, thinking, behavior, emotions, role of play, impairment and also unusual behavior.

Although there are several regular factors shown in most people with autism, Autism Spectrum Disorder (ASD) is a distributive developmental disorder within individuals in numerous degrees of impairment (Sicile, 2004). For example, although these autistic people look well, his gross motor control is lacking, by and large, he loves to interact with technology and video games and become attached to a particular interest like dinosaurs, trains or outer space.

\footnotetext{
* Corresponding Author.

Email Address: helmiadly@unikl.edu.my (H. A. M. Noor)

https://doi.org/10.21833/ijaas.2017.03.011

2313-626X/C) 2017 The Authors. Published by IASE.

This is an open access article under the CC BY-NC-ND license (http://creativecommons.org/licenses/by-nc-nd/4.0/)
}

The number of diagnosed autistic children is increasing. With regard to a great progress in early diagnosis, the results for a majority of autistic children are still unsatisfactory where few of them are able to live independently towards adulthood (Billstedt and Gillberg, 2005; Eaves and Ho, 2008; Howlin et al., 2004). In relation to that, ample research on serious game based for children with autism in the field of computing.

Visual perception problem is very common in autistic children. They often have difficulty in recognizing, remembering, organizing and interpreting visual images. As a result, they are easily confused in situations that involve using written or pictorial symbols for learning (Kurtz, 2006).

By and large, the term serious game has been utilised by many researchers. In a book entitled "Serious Games" the first author in his own work in educational-curriculum development, school-system planning, industrial management and technological planning and forecasting is illustrated. In which in order to train managers, students and teachers, he has examined war-games (a mixture of mathematical analysis and the group interaction) and simulations (Clark, 1970). In this paper, the aims are described below:

a) To review current serious games for autism 
b) To propose a new development framework

c) To describe the development of prototype

This paper has been divided into four parts. The first section deals with introduction, Section II describes the related works of serious games for autism and Section III presents the proposed development framework model. Finally, Section IV describes the development of prototype and the last section $\mathrm{V}$ concludes the paper and suggests future work for research.

\section{Related works}

Recently, therapy and education which include learning and training are the two main purposes for autism serious games development. Autism serious games for therapy have been done with the main purpose therapy for communication skill, visual motor coordination, social skill, sensory integration, concentration and social behaviours. Teaching and learning process by using serious games for education will help educators and students.

The purpose is to learn the concept of money, social skill, communication skill, first aid learning and narrative learning. Currently, there is no other serious game used as a tool to diagnose and assess visual perception problem for autistic children. Visual perception serious games will be a technological solution to diagnosed autistic children problems. The list of serious games for autism was proposed and adapted by Helmi et al. (2012a, 2012b and 2013), and it is shown in Table 1 and Table 2.

Table 1: Serious games for therapy of autistic children

\begin{tabular}{ccc}
\hline No. & Purposes/ Objectives & Author \\
\hline 1 & E-learning environment & Artoni et al. (2012) \\
2 & Teaching facial expression & Jain et al. (2012) \\
3 & Interaction skills measurement & Bartolome et al. (2013) \\
4 & Learning emotional and social skills & Yan (2011) \\
5 & Increasing intelligibility in speech & Sharmin et al. (2011) \\
6 & Speech delays & Hailpern et al. (2012) \\
7 & Teaching social conversation skills & Zancanaro et al. (2014) \\
8 & Exploring motion-based touchless games & Bartoli et al. (2013) \\
\hline
\end{tabular}

\section{Development framework}

The Development Framework was developed as shown in Fig. 1. This model shows the overall development framework model that served as a guide to engage all the referred diagnosis method. This was adapted to the development of the prototype design and research question solutions based on the Vi-Per Games development phase.

Vi-Per Games is a name for Visual Perception Games. In terms of content, the prototype Vi-Per Games was developed based on the ADDIE model. ADDIE stands for Analysis, Design, Development, Implementation, and Evaluation. It is a five-phase systematic model used to guide through the process of creating multimedia products for a variety of settings. Each phase of the ADDIE model is an important element of the design process. In each phase, decisions are made for ensuring the effectiveness of the game experience.

\section{Prototype development}

\subsection{Software}

The prototype was implemented on the Multimedia authoring tools which required to design the user interface of visual perception games. In other words, the combination of various tools made the system more powerful. The software involved in this study was (i) Adobe Illustrator CS5 (ii) Adobe Photoshop CS5, and (iii) Adobe Dreamweaver CS5. Adobe illustrator was needed in order to create and edit the needed image in visual perception games. These elements were then imported to flash. Below is a description of the software used in this study.

Table 2: Serious games for education of autistic children

\begin{tabular}{ccc}
\hline No. & Purpose/ Objective & Author \\
\hline 1 & Teaching emotion & Abirached et al. (2012) \\
2 & Social skills & Hourcade et al. (2012) \\
3 & Teaching vocational and daily living skills & Bereznak et al. (2012) \\
4 & Teaching basic skills & Hulusica and Pistoljevic (2012) \\
5 & Learning facial expressions & Hansen et al. (2013) \\
6 & Learning emotion expression & Piana et al. (2013) \\
7 & Natural social engagement & Chukoskie et al. (2013) \\
8 & Developing social skills & Chen (2013) \\
9 & Emotional learning environment & Bertacchini et al. (2013) \\
10 & Facial expression and emotion & Schuller et al. (2014) \\
11 & Learning words & Al-Khafaji et al. (2013) \\
12 & Emotion training in the context of financial decision-making & Jercic et al. (2012) \\
13 & Imaginative play & Bai (2012) \\
14 & Imaginative skills & Porayska et al. (2013) \\
15 & First Aid Learning & De Urturi et al. (2012) \\
\hline
\end{tabular}




\subsubsection{Adobe illustrator CS5}

Illustrator is important software or editing tool used in this study. It is a powerful program used in designing interface. It is also used to create layouts for buttons, icons, front pages and others. In addition, it offers a variety of features that make compositing multiple images easier than ever before.

\subsubsection{Adobe flash CS5}

Vi-Per Games used this software to provide features to support compliance with web accessibility guidelines by allowing for auto-labeling of buttons, tab-order controls and access to assistive technologies such as screen readers. The program's flexibility in learning object design means that the end user has the ability to choose how they want the information to be presented.

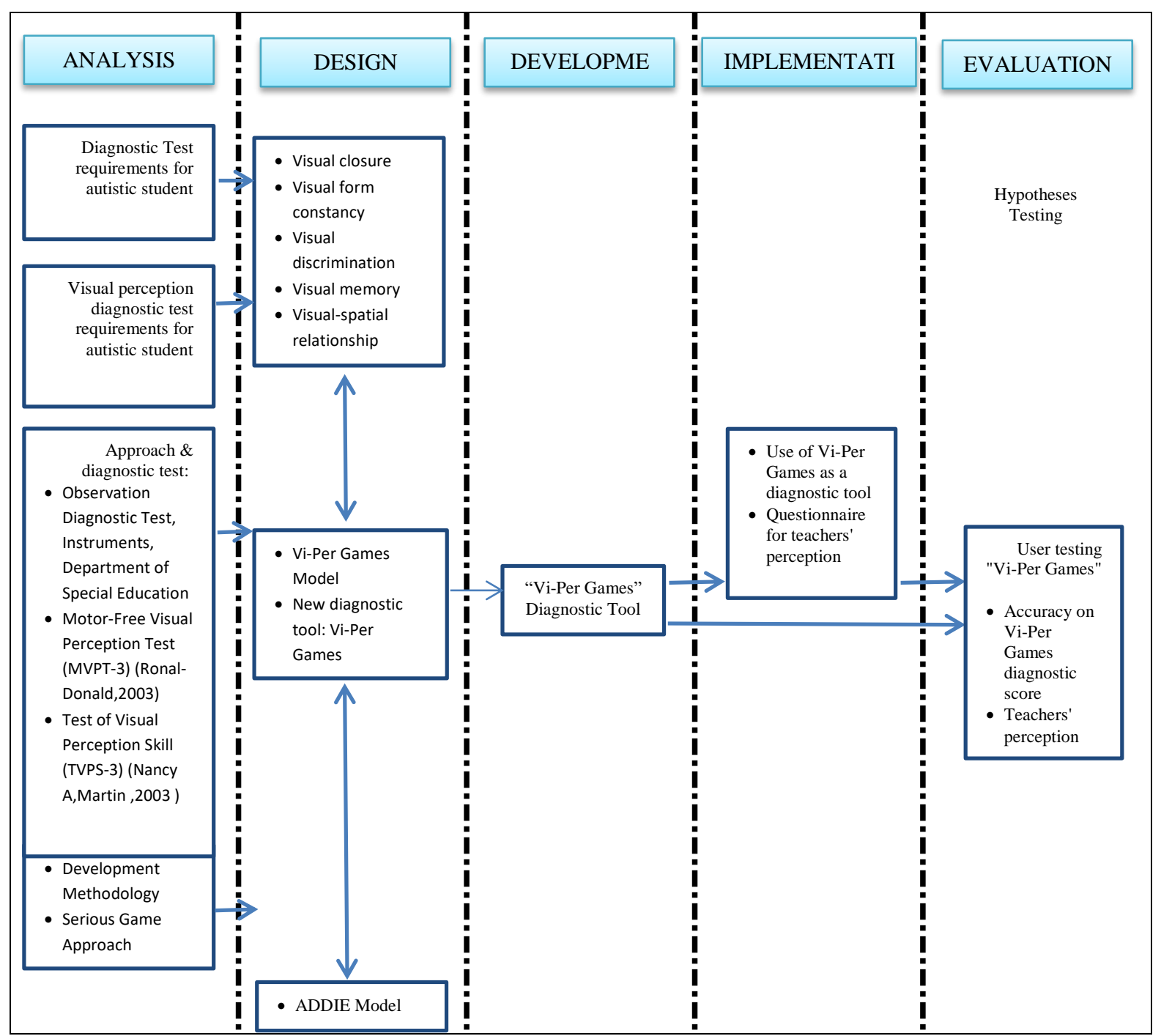

Fig. 1: Development framework

\subsubsection{Adobe dreamweaver CS5}

Adobe Dreamweaver CS5 was used in Vi-Per Games to design the web based environment. It delivers powerful new tools that support Hypertext Preprocessor (PHP) based content management system. The PHP is free software released under the PHP License and can be set up on most web servers. It is also a standalone shell on almost every operating system and platform for free.

\subsection{Game interface}

As the saying goes, a picture is worth a thousand words. Thus, it is essential to incorporate graphics in order to increase users' understanding. In this project, two types of graphics were incorporated, vector and bitmap. Vector graphics or vector images define the curves and shapes in a picture and they are stored as algorithms or a set of mathematics equations. Each game will start with the introduction montage (Fig. 2). Then, autism student can start with drag and drop playing games (Fig. 3). After finish the games, ending montage will play (Fig. 4).

\section{Conclusion and future work}

Serious game is relevant to help several problems such as autism. In this paper, a related work of current serious games for autism; a 
development framework model to diagnose visual perception problem for autism children and the development of prototype were discussed.

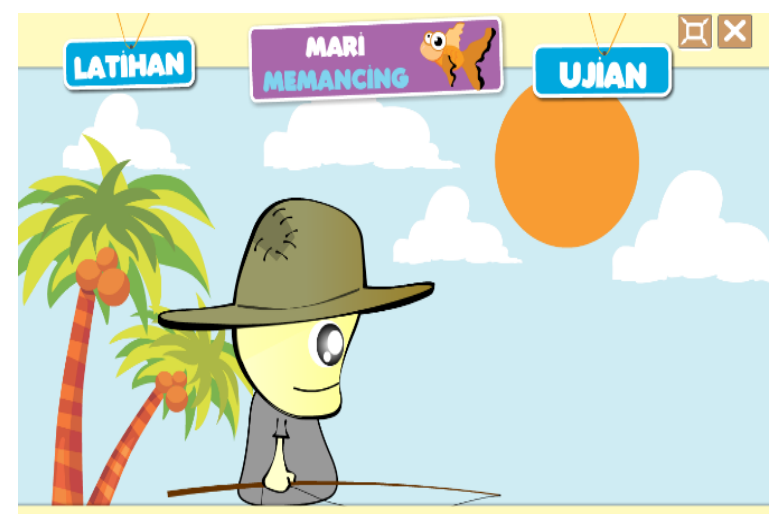

Fig. 2: Introduction to let's go fishing game 1 interface

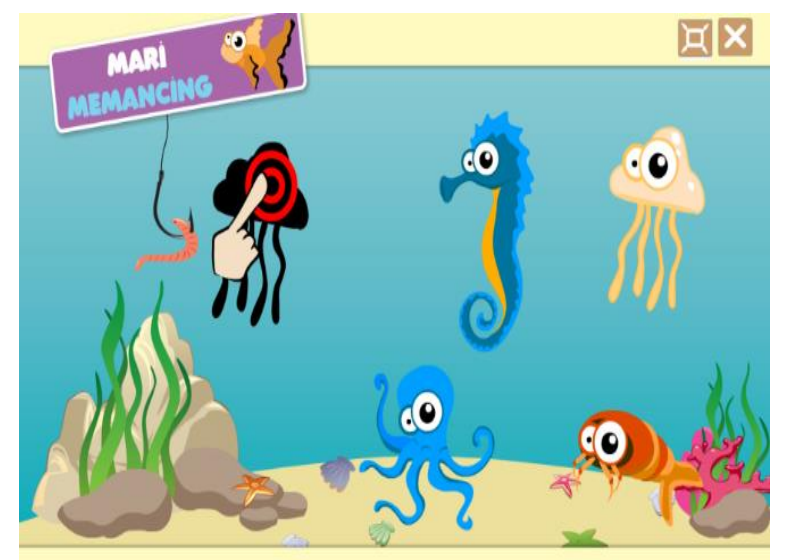

Fig. 3: Let's go fishing game 1 exercise interface

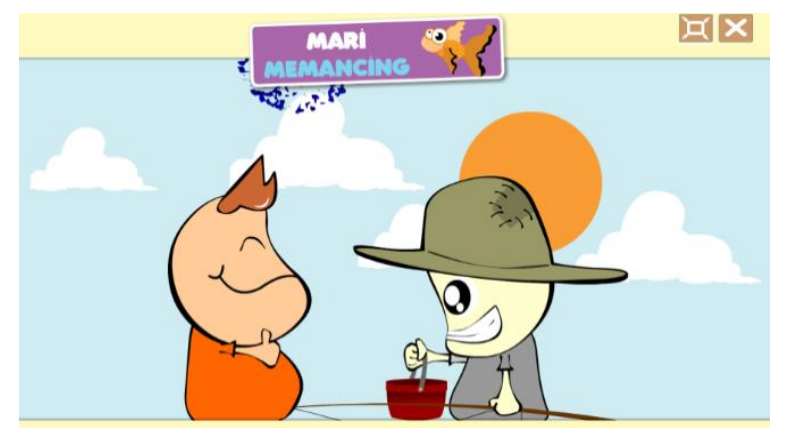

Fig. 4: Ending montage of let's go fishing game 1 interface

Serious games are a fresh alternative compared to this flat, rigid type of assessment. Insomuch that digital games can be assessed regularly by integrating other forms of conventional assessment with modern procedures. Additionally, this situation offers the opportunities to create assessment that is more intricate and complete. Future work should concentrate on the analyze result of visual perception diagnosis assessment by using serious game to identify visual perception problems among autism children.

\section{References}

Abirached B, Zhang Y, and Park J (2012). Understanding user needs for serious games for teaching children with autism spectrum disorders emotions. In the World Conference on
Educational Multimedia, Hypermedia and Telecommunications. AACE, Denver, Canada: 1054-1063.

Al-Khafaji N, Al-Shaher M, and Al-Khafaji M (2013). M-learning application for autistic children using Android platform. In the Future Trends in Computing and Communication: 16-19.

Artoni S, Buzzi MC, Buzzi M, Ceccarelli F, Fenili C, Rapisarda B, and Tesconi M (2012). Designing ABA-based software for lowfunctioning autistic children. In the $2^{\text {nd }}$ International Conference on Advances in New Technologies, Interactive Interfaces and Communicability (ADNTIIC'11). Huerta Grande, Argentina: 230-242. https://doi.org/10.1007/978-3642-34010-9_22

Bai Z (2012). Augmenting imagination for children with autism. In the $11^{\text {th }}$ International Conference on Interaction Design and Children. ACM, New York, USA: 327-330.

Bartoli L, Corradi C, Garzotto F, and Valoriani M (2013). Exploring motion-based touchless games for autistic children's learning. In the $12^{\text {th }}$ International Conference on Interaction Design and Children (IDC '13). New York, USA: 102-111. https://doi.org/10.1145/2485760.2485774

Bartolome NA, Zorrilla AM, and Zapirain BG (2013). Autism spectrum disorder children interaction skills measurement using computer games. In the $18^{\text {th }}$ International Conference on Computer Games: AI, Animation, Mobile, Interactive Multimedia, Educational and Serious Games (CGAMES). IEEE: 207-211. https://doi.org/10.1109/CGames.2013.6632634

Bereznak S, Ayres K, Mechling L, and Alexander J (2012). Video self-prompting and mobile technology to increase daily living and vocational independence for students with autism spectrum disorders. Journal of Developmental and Physical Disabilities, 24(3): 269-285.

Bertacchini F, Bilotta E, Gabriele L, Vizueta DE, Pantano P, Rosa F, Tavernise A, Vena S, and Valenti A (2013). An emotional learning environment for subjects with autism spectrum disorder. In the International Conference on Interactive Collaborative Learning (ICL). IEEE, Kazan, Russia: 653-659. https://doi.org/10.1109/ICL.2013.6644675

Billstedt E and Gillberg C (2005). Autism after adolescense: Population-based 13-22-year follow-up study of 120 individuals with autism diagnosed in childhood. Journal of Autism and Developmental Disorders, 35(3): 351-360.

Chen C (2013). Developing a tablet computer game with visualspatial concept jigsaw puzzles for autistic children. Available online at: http://design-cu.jp/iasdr2013/papers/2197-1b.pdf

Chukoskie L, Soomro A, Townsend J, and Westerfield M (2013). Looking' better: Designing an at-home gaze training system for children with ASD. In the $6^{\text {th }}$ International IEEE/EMBS Conference on Neural Engineering (NER). IEEE, San Diego, USA: 1246-1249. https://doi.org/10.1109/NER.2013. 6696166

Clark CA (1970). Serious games. Viking Press, New York, USA.

De Urturi ZS, Zorrilla AM, and Zapirain BG (2012). A serious game for Android devices to help educate individuals with autism on basic first aid. In: Sigeru O, Juan FDPS, Sara RG, Jose MM, Ana MB, and Juan MCR, (Eds.), Distributed Computing and Artificial Intelligence, 151: 609-616. Springer Berlin, Heidelberg, Germany.

Eaves LC and Ho HH (2008). Young adult outcome of autism spectrum disorders. Journal of Autism and Developmental Disorders, 38(4): 739-747.

Hailpern J, Harris A, and La B (2012). Designing visualizations to facilitate multisyllabic speech with children with autism and speech delays. In the Designing Interactive Systems Conference. ACM, New York, USA: 126-135.

Hansen OB, Abdurihim A, and McCallum S (2013). Emotion recognition for mobile devices with a potential use in serious games for autism spectrum disorder. In: Ma M, Oliveira MF, Petersen S, and Hauge JB (Eds.), International Conference on 
Serious Games Development and Applications, 8101: 1-14. Springer Berlin, Heidelberg, Germany.

Helmi AMN, Faaizah S, and Naim CP (2012a). Serious game for autism children: Review of literature. International Journal of Social, Behavioral, Educational, Economic, Business and Industrial Engineering, 6(4): 554-559.

Helmi AMN, Faaizah S, and Naim CP (2012b). A review of serious game for autism children. In the International Conference on Computer Games, Multimedia, and Allied Technology: 90-95.

Helmi AMN, Faaizah S, Naim CP, Nur FY, Mariana Y, Khoo LMS, and Kamaruzaman J (2013). Developing a hybrid visual perception game using the ADDIE approach for autism. Australian Journal of Basic and Applied Sciences, 7(3): 1-4.

Hourcade J, Bullock RN, and Hansen T (2012). Multitouch tablet applications and activities to enhance the social skills of children with autism spectrum disorders. Personal and Ubiquitous Computing, 16(2): 157-168.

Howlin P, Goode S, Hutton J, and Rutter M (2004). Adult outcome for children with autism. Journal of Child Psychology and Psychiatry, 45(2): 212-229.

Hulusica V and Pistoljevic N (2012). LeFCA: Learning framework for children with autism. Procedia Computer Science, 15: 4-16.

Jain S, Tamersoy B, Zhang Y, Aggarwal JK, and Orvalho V (2012). An interactive game for teaching facial expressions to children with autism spectrum disorders. In the $5^{\text {th }}$ International Symposium on Communications Control and Signal Processing (ISCCSP). IEEE, Roma, Italy: 1-4. https://doi.org/10.1109/ISCCSP.2012.6217849

Jercic P, Astor PJ, Adam MT, Hilborn O, Schaaff K, Lindley C, Sennersten C, and Eriksson J (2012). A serious game using physiological interfaces for emotion regulation training in the context of financial decision-making. In the European Conference on Information Systems (ECIS). Barcelona, Spain: 207-221.

Kanner L (1967). Autistic disturbances of affective contact. Acta Paedopsychiatrica, 35(4): 100-136.

Kurtz LA (2006). Visual perception problems in children with $\mathrm{AD} / \mathrm{HD}$, autism, and other learning disabilities: A guide for parents and professionals. Jessica Kingsley Publishers, London, UK.
Piana S, Stagliano A, Camurri A, and Odone F (2013). A set of fullbody movement features for emotion recognition to help children affected by autism spectrum condition. In the International Workshop on Intelligent Digital Games for Empowerment and Inclusion: 1-7.

Porayska PK, Anderson K, Bernardini S, Guldberg K, Smith T, Kossivaki L, Hodgins S and Lowe I (2013). Building an intelligent, authorable serious game for autistic children and their carers. In: Reid D, Katayose H, and Nijholt A (Eds.), Advances in Computer Entertainment, 8253: 456-475. Springer Berlin, Heidelberg, Germany.

Schuller B, Marchi E, Baron-Cohen S, O'Reilly H, Pigat D, Robinson P, Davies I, Golan O, Friedenson S, Tal S, Newman S, Meir N, Shillo R, Camurri A, Piana Stagliano AS, Bolte S, Lundqvist D, Berggren S, Baranger A, and Sullings N (2014). The state of play of ASC-inclusion: An integrated internet-based environment for social inclusion of children with autism spectrum conditions. In the $2^{\text {nd }}$ International Workshop on Digital Games for Empowerment and Inclusion (IDGEI '14). ACM, Haifa, Israel.

Sharmin M, Rahman A, Ahmed M, Rahman M, and Ferdous S (2011). Teaching intelligible speech to the autistic children by interactive computer games. In the ACM Symposium on Applied Computing (SAC '11). TaiChung, Taiwan: 1208-1209. https://doi.org/10.1145/1982185.1982450

Sicile KC (2004). Autism spectrum disorders: The complete guide to understanding autism. Berkley Publishing Group, New York, USA.

Wan NWA and Hisham A (2013). Aku bersyukur anakku autisme. Telaga Biru, Selangor, Malaysia.

Yan F (2011). A sunny day: Ann and Ron's world an Ipad application for children with autism. In the the $2^{\text {nd }}$ international conference on Serious Games Development and Applications (SGDA'11). Lisbon, Portugal: 129-138.

Zancanaro M, Giusti L, Bauminger ZN, Eden S, Gal E, and Weiss PL (2014). NoProblem! A collaborative interface for teaching conversation skills to children with high functioning autism spectrum disorder. In: Anton N (Eds.), Playful User Interfaces: 209-224. Springer, Singapore. 